\title{
'CONRAD' copolymers via condensation and radical polymerization: Is this approach realistic?
}

\author{
Stoyko Fakirov* \\ Centre for Advanced Composite Materials, Department of Mechanical Engineering, The University of Auckland, Building \\ 903 Room 240, 314 Khyber Pass Road, Newmarket Campus, Private Bag 92019, 1142 Auckland, New Zealand
}

A peculiarity of condensation polymers is their ability to break up to shorter segments in their melts at high temperature as recently discussed in detail (https://engineeringresearch.org/index.php/GJRE/ article/view/2153). This phenomenon is rather different from the thermo-oxidative degradation of polymers when the macromolecules decompose irreversibly to smaller chemically different molecules. In the case of condensation polymers the decomposition is reversible, that is the breaking of chemical bonds is paralleled by establishing new bonds like the broken ones and after cooling down of the melt the macromolecules are largely restored.

The described processes are proven reliably by means of small-angle neutron scattering (SANS) on blends of protonated and deuterated species (https:// doi.org/10.1021/ma00145a025, https://doi.org/ 10.1016/0032-3861(86)90039-X, https://doi.org/ 10.1016/0032-3861(89)90001-3).

The frequency of breaking of chemical bonds depends on temperature - from approximately 10 transesterification reactions occurring per molecule per minute at $280^{\circ} \mathrm{C}$ (for PET) (https://doi.org/10.1021/ ma00171a041) up to more than 100 ester interchange reactions per chain per second at $450^{\circ} \mathrm{C}$ (for a 50/50 mixture of two homopolyesters) (https:// doi.org/10.1021/ma00208a041).

Possibly, the dissipated shorter segments in the melts of condensation macromolecules are of radical type, (as postulated in https://doi.org/10.1088/1755-1315/ $167 / 1 / 012029$ for calculation of the breaking energy), which recombine permanently and thus make possible restoration of macromolecules.

An interesting situation could be created by introducing olefin type radicals into the melt of a condensation polymer. They are supposed to be involved in recombination reactions resulting in formation of condensation-radical ('con-rad') copolymers. The case is rather similar to the melt blending of two or more condensation homopolymers resulting in preparation of condensation copolymers (https:// doi.org/ 10.1016/j.progpolymsci.2018.09.003).

The suggested approach for preparation of condensation-radical copolymers seems to be more attractive than the existing rather complex ones (e.g. https://doi.org/10.1021/ma981924y).

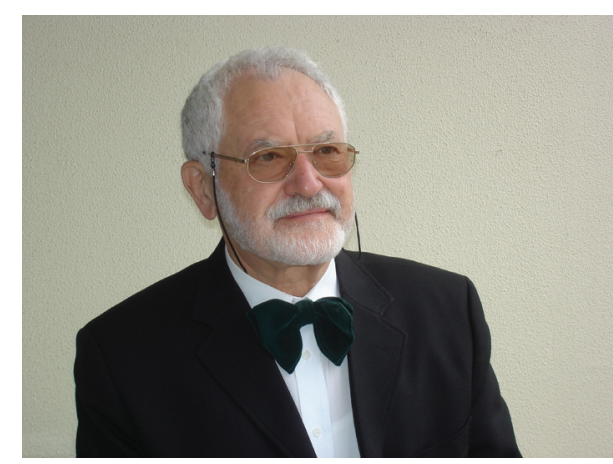

Prof. Dr. Stoyko Fakirov Member of the Executive Editorial Board

\footnotetext{
*Corresponding author, e-mail: s.fakirov@auckland.ac.nz (C) BME-PT
} 